\title{
Japon Bıldırcınlarında Karkas Ağırlığına Etki Eden Bazı Karkas Parça Ölçülerinin Path Analizi ile İncelenmesi
}

\author{
Hakan İNCí ${ }^{1}$, Şenol ÇELİK ${ }^{1}$, Tugay AYAŞAN ${ }^{2 *}$ \\ ${ }^{1}$ Bingöl Üniversitesi, Ziraat Fakültesi, Zootekni Bölümü, Bingöl \\ ${ }^{2}$ Doğu Akdeniz Tarımsal Araştırma Enstitüsü Müdürlüğü, Yemler ve Hayvan Besleme Bölümü, Adana
}

Geliş (Received): 11.02.2016

Kabul (Accepted): 19.04.2016

\begin{abstract}
ÖZET: Bu çalışmada, Japon bıldırcınlarında karkas ağırlığı üzerinde but ağırlı̆̆ı, göğüs ağırlı̆̆ı, kanat ağırlığı ve sırt ağırlığı ölçülerinin doğrudan ve dolaylı etkileri path analizi ile belirlenmiş̧ir. Çalışmada 40 adet Japon bıldırcınına (Coturnix coturnix Japonica) ait ölçütler kullanılmıştır. Bıldırcınların yarısı erkek yarısı da dişidir. Analiz sonuçlarına göre bıldırcınlarda karkas ağırlığı ile incelenen karkas parça ağırlıkları arasındaki ilişkinin pozitif ve önemli olduğu saptanmıştır $(P<0.05)$. Denemede en yüksek korelasyona, karkas ağırlığı ile göğüs ağırlığı arasında rastlanılmıştır $(\mathrm{r}=0.775)$. Erkek bıldırcınlarda karkas ağırlığı ile karkas parça ölçüleri arasındaki ilişki önemsiz saptanırken; dişi bıldırcınlarda karkas ağırlığı ile göğüs ağırlı̆̆g ve sırt ağırlığı arasındaki ilişki önemli bulunmuştur $(\mathrm{P}<0.01)$. Çalışmada hem erkek hem de dişi bildırcınlarda en yüksek korelasyon, karkas ağırlığı ile göğüs ağırlığı arasında elde edilmiştir ( $\mathrm{r}=0.370$ ve $\mathrm{r}=0.797)$. Karkas ağırlı̆ğ üzerine but ağırlığı, göğüs ağırlığ 1 , kanat ağırlı̆̆ ve sırt ağırlığının doğrudan etkisi sırasıyla \%45.423, \%60.829, \%30.045 ve \%48.587 olarak bulunmuştur. Karkas ağırlığı üzerine en büyük doğrudan etkiyi göğüs ağırlığ 1 yapmıştır. Göğüs ağırlığının but ağırlı̆̆ı, kanat ağırlığı ve sırt ağırlığı üzerinden dolaylı etkileri sırasıyla \%17.231, \%5.931 ve \%15.989 olarak saptanmıştır.
\end{abstract}

Anahtar Kelimeler: Japon bıldırcını, Karkas ağırlığı, Path analizi, Karkas parça ağırlıkları

\section{Examination of Some Carcass Parts Measurements Affecting on Carcass Weight via Path Analysis on Japanese quail}

\begin{abstract}
In this study, direct and indirect effects of the thigh weight, breast weight, wing weight and back weight measure on carcass weight were determined by means of path analysis methods in Japanese quail. Forty Japanese quail (Coturnix coturnix Japonica), (half male and half female) were used in the study. The results show that examined relations carcass weight and all body measurements were significant $(\mathrm{P}<0.05)$. There was at the maximum correlation between carcass weight and breast weight $(\mathrm{r}=0.775)$. While the relationship between carcass weight and carcass part size was insignificant in the men quail. Whereas, the relationship between carcass weight with breast weight and back weight was significant in the female quail $(\mathrm{P}<0.01)$. There was also the maximum correlation between carcass weight and breast weight in both male and females ( $\mathrm{r}=0.370$ and $\mathrm{r}=0.797)$. Percentages of direct effects on carcass weight were $45.423 \%, 60.829 \%, 30.045 \%$ and $48.587 \%$ for the thigh weight, breast weight, wing weight and ridge weight, respectively. Breast weight sustained the largest direct effect on carcass weight. Indirect effects of breast weight through thigh weight, wing weight and ridge weight were $17.231 \%, 5.931 \%$ and $15.989 \%$, respectively.
\end{abstract}

Key Words: Japanese quail, Carcass weight, Path analysis, Carcass part weights

\section{GíRiş}

Japon bildırcinı, (Coturnix coturnix Japonica) üretimi son yıllarda hızla yaygınlaşan bir kanatlı türüdür. İnsan beslenmesinde önemli bir hayvansal protein kaynağı olması sebebiyle de her geçen gün önemi de artmaktadır. Japon bıldırcını, düşük vücut ağırlığına sahip olmasına rağmen eti ve yumurtası için ticari üretimde kullanılmaktadır. Bunun yanı sıra, 3-4 ay gibi kısa bir kuşak aralığına ve yüksek döl verimine sahip olması nedeniyle kanatlı hayvan ıslahı çalışmalarında model hayvan olarak da kullanılmaktadır (Marks, 1991; Ayaşan, 2013). Diğer kanatlı yetiştiriciliğine göre bıldırcın yetiştiriciliği çok dar bir alanda fazla miktarda yatırım gerektirmeden, k1sa sürede yüksek verim elde edilebilmesi, aile tipi üretime imkan verebilmesi bakımından da günümüzde giderek yaygınlaşan bir dal olmuştur (Poyraz ve ark. 2002;
Akınc1 ve ark. 2005; Alkan ve ark. 2008). Bildırcınlar hastalıklara karşı diğer kanatlı çiftlik hayvanlarına göre dayanıklıdır (Toelle ve ark. 1991; Tarhyel ve ark. 2012).

Bıldırcınlar coturnix familyasına ait olup bu türün 12 'den fazla alt türü bulunmaktadır. Erkek Japon bıldırcınları yaklaşık $16 \mathrm{~cm}$ boya ulaşırken dişiler ise yaklaşık $18.5 \mathrm{~cm}$ boya ulaşmaktadır. Erkekler dişilerden daha düşük bir canlı ağırlık ve beden yapısına sahiptir (Vatansever, 1998). Bu konuda yapılan başka bir çalışmada Baylan ve ark. (1997), bıldırcınlarda dişilerin 5. ve 6. hafta yaşlarında erkeklerden daha iyi gelişip, daha yüksek canlı ağırlık kazandıklarını, yem tüketimi ve yemden yararlanmada da daha iyi sonuçlar verdiğini tespit etmişlerdir.

Japon bıldırcınlarında et kalitesi ile ilişkili karakterlerin kalıtımının konu edildiği bazı çalışmalar bulunmaktadır (Kawahara ve Saito, 1976; Toelle ve ark. 
1991; Schuler ve ark. 1996; Bahie El-Deen, 2001; Oğuz ve Minvielle, 2001; Oğuz ve ark. 2004a; Oğuz ve ark. 2004b). Gevrekçi ve ark. (2009), bıldırcınlarda et kalite özelliklerinin maksimum olabilirlik, kısıtlanmış maksimum olabilirlik (REML) ve en küçük varyanslı ikinci dereceden yansiz tahminleyici (MIVQUE) ile elde edilen kalıtım derecesi tahminlerini orta düzeyden yüksek düzeye değişim gösterdiğini bildirmişlerdir. Zerehdaran ve ark. (2012), et kalite özelliklerinin genetik seleksiyon yoluyla geliştirildiğini, ancak yüksek vücut ağırlığı ve karkas kompozisyonu seleksiyonunda, kas içi yağ ve artan hafiflik, et pişirme kaybının Japon bıldırcınlarında et kalitesini düşürdüğünü bildirmişlerdir. Narinç ve ark. (2013), bıldırcınlarda en kalıtsal et kalite özelliğini $\mathrm{pH}=0.64$ olarak saptamışlardır. $\mathrm{pH}$ değeri göğüs verimi hariç, vücut ağırlığ 1 ve abdominal yağ verimi ile negatif ancak yüksek korelasyon ilişkisi gösterirken, parlaklık (lightness) değeri ise, vücut ağırlığı, göğüs verimi ve abdominal yağ verimi ile pozitif ilişkiye sahiptir. Oğuz ve Minvielle (2001) çalışmalarında, Japon bıldırcınlarının karkas ve et kalitesi ile ilişkili karakterlerinin genellikle orta ve yüksek düzeyde kalıtsal olduğunu belirtmişlerdir. Khaldari ve ark. (2010), 4 haftalık bıldırcınlarda vücut ağırlığı ve karkas özellikleri arasında güçlü bir genetik ilişki olduğunu bildirmişlerdir ve karkas özelliklerini geliştirerek bir seleksiyon kriteri olarak kullanılacağını önermişlerdir. Narinç ve ark. (2010), bıldırcınlarda karkas, göğüs, but ve abdominal yă̆ ağırlıkları için kalıtım derecelerini sirasiyla $0.42,0.36,0.34$ ve 0.40 olarak; karkas, gögüs, but ve abdominal yağ randımanı için kalıtım derecelerini sirasiyla $0.11,0.18,0.12$ ve 0.29 olarak saptamışlardır. Lotfi ve ark. (2011), bıldırcınlarda vücut ağırlığı ve karkas özellikleri ağırlığı kalıtım tahminlerini (vücut ağırlığı için 0.45 ve gögüs eti ağırlığı için 0.63 ), karkas özellikleri randımanından (uyluk randımanı için 0.11 ve göğüs eti randımanı için 0.19) daha yüksek olarak tespit etmişlerdir. Sarı ve ark. (2011), bıldırcınlarda soğuk karkas, göğüs, but, kanat ve karaciğer ağırlıklarına ait kalıtım değerlerini sırasıyla $0.55,0.58,0.54,0.49$ ve 0.13 olarak saptamışlardır.

Japon bıldırcınlarının karkas özelliklerine ilişkin çalışmalar incelendiğinde, bildırcınlarda karkas ağırlıklarının eşeylere göre farklılık gösterdiği görülmüştür. Dişi bıldırcın karkası erkeğinkine göre daha ağırdır). Ayaşan ve ark. (2000), beşinci hafta karkas ağırlığını gruplara göre ortalama olarak 124.17 ile $142.83 \mathrm{~g}$ olarak tespit etmişlerdir. Kanatl hayvanlarda gögüs eti oranı en fazla olarak ilk sırada bildircin, ikinci sirada ise hindiler yer almaktadır (Camc1, 1992). Gögüs ağırlığ $21.9 \mathrm{~g}$ ile $38.51 \mathrm{~g}$ arasında, oransal göğüs ağırlığı da \% 19.94 ile \% 40 arasında değişim göstermiştir (Wyatt ve ark. 1982; Ayaşan ve ark. 2000). Tarhyel ve ark. (2012), $6,8,10,16,20,24,30$ ve 52 haftalık bildırcinlarda canlı ağırlıkları sırasıyla 97.19 g, 119.93 g, 132.00 g, 134.44 g, 129.72 g, $142.11,154.33 \mathrm{~g}$ ve $162.67 \mathrm{~g}$; karkas ağırlıklarını ise $67.60 \mathrm{~g}, 86.57 \mathrm{~g}, 93.42 \mathrm{~g}, 92.35 \mathrm{~g}, 89.82$ $\mathrm{g}, \quad 96.98 \mathrm{~g}, 104.14 \mathrm{~g}$ ve $119.54 \mathrm{~g}$ olarak tespit etmişlerdir. Narinç ve ark. (2014), kontrol hattındaki 4, 5, 6, 7 ve 8 haftalık yaştaki Japon bıldırcınlarının vücut ağırlıklarını sırasıyla 141.6, 164.5, 181.6, 187.7 ve $195.4 \mathrm{~g}$; soğuk karkas ağırlıklarını sırasıyla 100.5, $113.8,123.7,128.1$ ve $130.4 \mathrm{~g}$ olarak saptamışlardır. Seleksiyon grubundaki bıldırcınlarda ise aynı yaşlarda canlı ağırlıkları sırasıyla 164.1, 194.8, 211.8, 220.5 ve $225.6 \mathrm{~g}$; soğuk karkas ağırlıklarını sırasıyla 118.4, $139.4,146.0,149.7$ ve 152.5 g olarak saptamışlardır.

$\mathrm{Bu}$ çalışmaya teşkil olan path analizi, verim ve verime etkili faktörler arasındaki doğrudan ve dolaylı etkilerin birbirinden ayrılarak incelenmesini sağlayan bir yöntem olup; path analizinin amac1, değişkenler arasındaki nedensel ilişkiler için oluşturulmuş hipotezlerin önemliliğini ve miktarını tahmin etmektir (Daşdağ ve ark. 2006).

Pym ve ark. (1998) canlı ağırlığın yanı sıra göğüs eti karakterlerini de dikkate alarak doğrudan seleksiyon yapmışlardır. Bu araştırıcılar, hem canlı ağırlığı hem de göğüs kası uzunluğu, genişliği ve derinliğine ilişkin ultrason ölçümlerini esas alan tahminleme denklemlerini kullanarak göğüs ağırlığı için; BWI hattında (göğüs eti ağırlığının-randıman- (g) artırılması yönünde seleksiyon yapılmış) yüksek fenotipik kazanç (10 gramdan fazla), BPI hattında (gögüs eti oranının (g/kg) artırılması yönünde seleksiyon yapılmış) ve LWI hattında (42. gün canlı ağırlığının artırılması yönünde seleksiyon yapılmış) orta düzeyde pozitif artış (yaklaşık 5 gram), BPD hattında (gögüs eti oranının azaltılması yönünde seleksiyon yapılmış) ise orta düzeyde negatif azalış (10 gramdan düşük) elde etmişlerdir. BPI ve BPD hatlarının ters yönlerdeki seleksiyonu başarılı olmuştur. Bıldırcınlarda canlı ağırlık üzerine yapılan seleksiyon çalışmalarının hemen hepsi, seleksiyonun; tüm karkas parçalarının ağırlıkları üzerinde de oldukça etkili olduğunu göstermiştir (Oguz ve Türkmut, 1999). Khaldari ve ark. (2011), 4 haftalık bildırcınlarda vücut ağırlığı ve karkas özellikleri arasında güçlü ilişki olduğunu, karkas özelliklerinin seleksiyon kriteri olarak kullanılabileceğini bildirmişlerdir. Khaldari ve ark. (2011), bıldırcınlarda göğüs ağırlığını arttırmak için genetik ilişki olarak vücut ağırlığının kullanılabileceğini önermişlerdir. Khaldari ve Ghiasi (2015), bıldırcınlarda vücut ağırlığı ve karkas özellikleri arasında güçlü bir korelasyon olması nedeniyle canlı ağırlığın karkas özelliğini geliştirmek için seleksiyon kriteri olarak kullanılabileceğini bildirmişlerdir. Narinç ve ark. (2015), sürü olarak yetiştirilen 5 haftalık bıldırcınlarda vücut ağırlığını birincil seleksiyon kriteri olarak belirlemişlerdir. Böylece bıldırcınlarda vücut ağırlığı, karkas ağırlığı ve göğüs ağırlığı gibi ölçülerin seleksiyon çalışmalarında önemli kriter olduğu anlaşılmaktadır. Karkas ağırlığı üzerinde diğer karkas parçalarının doğrudan ve dolaylı etkilerinin bilinmesi gereklidir. Path analizi bu etkileri araştırmak için geliştirilmiş bir yöntemdir. Regresyon ve korelasyon 
analizi bağımlı değişken üzerinde bağımsız değișkenlerin dolaylı etkilerini belirleyemediği için yeterli olamamaktadır. Dolayısıyla path analizi regresyon ve korelasyon analizine alternatif bir yöntemdir.

Bu çalışma ile Japon bıldırcınlarında, but ağırlığı, göğüs ağırlığı, kanat ağırlığı ve sırt ağırlığının karkas ağırlığı üzerindeki doğrudan ve dolaylı etkilerinin path analizi ile araştırılması amaçlanmıştır.

\section{MATERYAL ve METOT}

Araştırmanın hayvan materyalini, Bingöl Üniversitesi Ziraat Fakültesi Zootekni Bölümüne ait kanatlı hayvan ünitesinde yetiştirilen 20 adet erkek ve 20 adet dişi olmak üzere toplam 40 adet Japon bıldırcını (Coturnix coturnix Japonica) oluşturmuştur. Bıldırcınlar çok katlı bıldırcın kafeslerinde barındırılmışlardır. Deneme odasının aydınlatılması için, ikişer adet 60 Watt'lık ampul, 1sitma için otomatik olarak 1sıya ayarlanabilen elektrikli soba kullanılmıștır. Oda üç eșit bölmeye ayrılmış ve her bölmede $8 \mathrm{~cm}$ kalınlıkta odun talaşı ve saman karışımı altlık kullanılmıştır. Deneme süresince rasyonlar toz yem formunda verilmiş olup, hayvanların önlerinde daima temiz su bulundurulmasına özen gösterilmiştir. Deneme, 7 hafta süreyle yürütülmüştür. Bıldırcınların deneme süresince canlı ağırlık artışlarına ait ortalama değerler, yem tüketimi ve karkas özellikleri olarak; sıcak-soğuk tüm karkas, but, göğüs, kanat, sırt, boyun ve yenilebilir iç organ ağırlıkları tespit edilmiştir. Karkas öğelerine ayırma işlemi "Kentucky Fry Chicken, 9 piece Cuttig" yöntemine göre yapılmıştır. Hayvanlara ait karkas ağırlığ1 $(\mathrm{Y})$, but ağırlığ $\left(\mathrm{X}_{1}\right)$, göğ̈üs ağırlığı $\left(\mathrm{X}_{2}\right)$, kanat ağırlığ $\left(_{3}\right)$ ve sirt ağırlığı $\left(X_{4}\right)$ gram olarak ölçülmüştür.

Sewall Wright tarafindan 1921 y1lında önerilen path katsayısı, etkisi belirlenen değişken dışındaki bağımsız değişkenler sabit olduğunda, bağımlı değişkende gözlenen standart sapmanın bağımsız değişkenden kaynaklanan kısmı olarak tanımlanmıştır (Pedhazur, 1997).

İki değişken arasında hesaplanan korelasyon katsayısının içerisinde, değişkenlerin tek başına etkisi ve diğer değişkenler ile olan birlikte etkileri (dolaylı etkiler) bulunduğundan, değişkenlerin ayrı ayrı ve birlikte etkilerini bulmak gerektiğinde, path analizi tekniği kullanılır (Singh ve ark. 1988). Path analizinde her bir bağımsız (sebep) değișkeninin etki miktarı açıklandığı için modele girebilecek bağımsız değişkenlerin seçimi önemlidir (Sokal ve Rohlf, 1995). $\mathrm{Bu}$ nedenle değişkenler arasında sebep sonuç ilişkilerinin araștırmacı tarafından belirlenerek buna göre analiz yapılmalıdır (Pek, 1999).

Bir path katsayısı, path modeldeki bir bağımlı değişken üzerinde bağımsız değişkenin doğrudan etkisini gösteren standartlaştırılmış regresyon katsayısıdır (Alpar, 2011). Path katsayıları Eşitlik (1) de olduğu gibi hesaplanabilir (Mendeş ve ark. 2005; Yakubu ve Salako, 2009).

$$
\mathrm{P}_{\mathrm{YX}_{\mathrm{i}}}=\frac{\hat{\beta}_{\mathrm{i}} \mathrm{S}_{\mathrm{X}_{\mathrm{i}}}}{\mathrm{S}_{\mathrm{Y}}}
$$

Burada $\mathrm{P}_{\mathrm{YX}_{\mathrm{i}}}$ : Path katsayıları veya $\mathrm{X}_{\mathrm{i}}$ 'den $\mathrm{Y}^{\prime} \mathrm{ye}$ standartlaştırılmış regresyon katsayılarıdır, $\hat{\beta}_{\mathrm{i}}$ :Standartlaştırılmamış regresyon katsayısı, $\mathrm{S}_{\mathrm{X}_{\mathrm{i}}}$ : $\mathrm{X}_{\mathrm{i}}^{\prime}$ 'nin standart sapması, $\mathrm{S}_{\mathrm{Y}}$ : Y'nin standart sapmasıdır.

Bağımsız değişkenlere ait doğrudan etkiler dikkate alınarak, sözü edilen değişkenlerin bağımlı değişken üzerinde yaptıkları dolaylı etkiler de hesaplanabilir. Bunun için (1) no'lu eşitlikten yararlanarak oluşturulan path katsayıları diyagonal (köşegen) matrisi ile bağımsız değişkenlerin oluşturduğu korelasyon matrisi çarpılarak dolaylı etkilerden oluşan (2) no'lu eşitlikteki matris elde edilir.

Eşitlik (2)'de verilen eşitliğin solundaki matriste köşegen üzerindeki değerler path katsayılarını yani doğrudan etkileri, köşegen dişındaki değerler de bağımsız değişkenlerin birbirleri üzerinden dolaylı etkilerini ifade etmektedir. Regresyon analizi ve korelasyon katsayıları SPSS 22.0 paket programı ile, Path analizi için diğer hesaplamalar MATLAB 12 paket programı ile yapılmıştır.

$$
\left[\begin{array}{llll}
\mathrm{P}_{\mathrm{Y} 1} & \mathrm{P}_{\mathrm{Y} 1} \mathrm{r}_{12} & \mathrm{P}_{\mathrm{Y} 1} \mathrm{r}_{13} & \mathrm{P}_{\mathrm{Y} 1} \mathrm{r}_{14} \\
\mathrm{P}_{2} \mathrm{r}_{21} & \mathrm{P}_{\mathrm{Y} 2} & \mathrm{P}_{\mathrm{Y} 2} \mathrm{r}_{23} & \mathrm{P}_{\mathrm{Y} 2} \mathrm{r}_{24} \\
\mathrm{P}_{3} \mathrm{r}_{31} & \mathrm{P}_{\mathrm{Y} 3} \mathrm{r}_{32} & \mathrm{P}_{\mathrm{Y} 3} & \mathrm{P}_{\mathrm{Y} 3} \mathrm{r}_{34} \\
\mathrm{P}_{4} \mathrm{r}_{41} & \mathrm{P}_{\mathrm{Y} 4} \mathrm{r}_{42} & \mathrm{P}_{\mathrm{Y} 4} \mathrm{r}_{43} & \mathrm{P}_{\mathrm{Y} 4}
\end{array}\right]=\left[\begin{array}{llll}
\mathrm{P}_{\mathrm{Y} 1} & 0 & 0 & 0 \\
0 & \mathrm{P}_{\mathrm{Y} 2} & 0 & 0 \\
0 & 0 & \mathrm{P}_{\mathrm{Y} 3} & 0 \\
0 & 0 & 0 & \mathrm{P}_{\mathrm{Y} 4}
\end{array}\right]\left[\begin{array}{cccc}
1 & \mathrm{r}_{12} & \mathrm{r}_{13} & \mathrm{r}_{14} \\
\mathrm{r}_{21} & 1 & \mathrm{r}_{23} & \mathrm{r}_{24} \\
\mathrm{r}_{31} & \mathrm{r}_{32} & 1 & \mathrm{r}_{34} \\
\mathrm{r}_{41} & \mathrm{r}_{42} & \mathrm{r}_{43} & 1
\end{array}\right]
$$

\section{BULGULAR ve TARTIŞMA}

Japon bildırcinlarının genel olarak ve cinsiyete göre karkas ağırlığ $(Y)$, but ağırlığ $1\left(X_{1}\right)$, göğüs ağırlığ ${ }_{1}\left(X_{2}\right)$, kanat ağırlığı $\left(\mathrm{X}_{3}\right)$ ve sirt ağılığına $\left(\mathrm{X}_{4}\right)$ ait tanıtıcı istatistikler Çizelge 1'de verilmiştir. Standardize edilmiş ve normal regresyon katsayıları, standart hata, $t$ istatistikleri ve önem düzeyleri ile modelin belirtme katsayısı $\left(\mathrm{R}^{2}\right)$ tüm bıldırcınlar, erkek ve dişi bıldırcınlar için ayrı ayrı olarak Çizelge 2'de sunulmuştur. Japon bıldırcınlarında üzerinde durulan değişkenlere ait 
korelasyon katsayıları ve önem düzeyleri Çizelge 3'de sunulmuştur. Karkas ağırlığına etki eden karkas parçaları ölçülerinin doğrudan ve dolaylı etkileri tespit edilmiştir. Tespit edilen bu etkilerin değerleri tüm bıldırcınlar, erkek ve dişi bıldırcınlar için Çizelge 4'de verilmiştir.

Denemeye alınan 40 adet bildırcinın ortalama olarak karkas ağırlığ $174.88 \mathrm{~g}$, but ağırlığı $27.08 \mathrm{~g}$, göğüs ağırlı̆̆ $54.79 \mathrm{~g}$, kanat ağırlığ $8.55 \mathrm{~g}$ ve sirt ağırlığı da 38.73 g olarak saptanmıştır.

Erkek bıldırcınların ortalama karkas ağırlığı 158.11 $\mathrm{g}$, but ağırlığı $24.91 \mathrm{~g}$, göğüs ağırlığı $50.71 \mathrm{~g}$, kanat ağırlığı $8.04 \mathrm{~g}$ ve sırt ağırlığı $38.53 \mathrm{~g}$; diși bıldırcınların ortalama karkas ağırlı $\breve{g}_{1} 191.65 \mathrm{~g}$, but ağırlı $\breve{g}_{1} 29.25 \mathrm{~g}$, göğüs ağırlığı $58.86 \mathrm{~g}$, kanat ağırlığ $9.06 \mathrm{~g}$ ve sirt ağırlı̆ğ da $38.93 \mathrm{~g}$ olarak tespit edilmiştir. Karkas ağırlı̆̆ı Yolcu ve ark. (2006)'nın buldukları değerlerden daha yüksek, Alkan ve ark. (2013)'ün buldukları değere yakın çıkmıştır. Göğüs ağırlığı Yolcu ve ark. (2006)'nın buldukları değerlere yakın, Alkan ve ark. (2013)'nın buldukları değerden daha yüksek çıkmıştır. Bonos ve ark. (2010), 6 haftalık yașta Japon bıldırcınlarında göğüs randımanını gruplarda 33.92-36.02 g arasında tespit ederken; karkas ağırlı̆ıını da 124.75-142.40 arasında bulmuşlardır. Kosshak ve ark. (2014), göğüs ağırlığını 40.66-42.83 g arasında tespit etmișlerdir.

Cizelge 1. Japon bıldırcınlarında cesitli karkas parçaları ağırlıklarına ait tanıtıcı istatistikler Bıldırcınlar (Erkek+Dişi)

\begin{tabular}{|c|c|c|c|c|c|}
\hline Değişken & $\mathrm{N}$ & $\bar{X}$ & $S_{\bar{x}}$ & En küçük & En büyük \\
\hline Karkas & 40 & 174.88 & 3.88 & 132.99 & 243.05 \\
\hline But & 40 & 27.08 & 0.59 & 19.55 & 33.69 \\
\hline Göğüs & 40 & 54.79 & 1.30 & 43.55 & 77.32 \\
\hline Kanat & 40 & 8.55 & 0.19 & 5.30 & 11.30 \\
\hline Sirt ağırlığ 1 & 40 & 38.73 & 1.33 & 28.17 & 60.71 \\
\hline \multicolumn{6}{|c|}{ Erkek bildırcınlar } \\
\hline Karkas & 20 & 158.11 & 2.95 & 132.99 & 184.37 \\
\hline But & 20 & 24.91 & 0.77 & 19.55 & 30.79 \\
\hline Göğüs & 20 & 50.71 & 1.15 & 43.45 & 61.90 \\
\hline Kanat & 20 & 8.04 & 0.29 & 5.30 & 11.30 \\
\hline Sirt ağırlığ 1 & 20 & 38.53 & 1.78 & 28.17 & 53.20 \\
\hline \multicolumn{6}{|c|}{ Dişi bıldırcınlar } \\
\hline Karkas & 20 & 191.65 & 4.84 & 149.48 & 243.05 \\
\hline But & 20 & 29.25 & 0.57 & 23.77 & 33.69 \\
\hline Göğüs & 20 & 58.86 & 1.96 & 43.67 & 77.32 \\
\hline Kanat & 20 & 9.06 & 0.19 & 7.87 & 10.99 \\
\hline Sirt ağırlığ 1 & 20 & 38.93 & 2.03 & 30.35 & 60.71 \\
\hline
\end{tabular}

$\bar{X}$ : Ortalama, $s_{\bar{x}}:$ Standart hata

Cizelge 2. Japon bıldırcınlarının karkas parçaları ölçülerine ait regresyon analizi sonuçları

\begin{tabular}{|c|c|c|c|c|c|}
\hline \multicolumn{6}{|c|}{ Bıldırcınlar (Erkek+Dişi) } \\
\hline Karkas ağırlı̆̆ $1(Y)$ & Katsay1 & Standart Hata & $\mathrm{t}$ & $\mathrm{P}$ & Beta \\
\hline Sabit & -24.88 & 23.336 & -1.066 & 0.294 & \\
\hline But ağırlı $\breve{g}_{1}$ & 2.138 & 0.883 & 2.421 & 0.021 & 0.323 \\
\hline Göğüs ağırlığ 1 & 1.411 & 0.363 & 3.892 & 0.000 & 0.472 \\
\hline Kanat ağırlı̆̆ & 3.557 & 2.365 & 1.504 & 0.142 & 0.172 \\
\hline Sirt ağırlığ 1 & 0.882 & 0.335 & 2.635 & 0.012 & 0.304 \\
\hline \multicolumn{6}{|l|}{$\mathrm{R}^{2}=0.727$} \\
\hline \multicolumn{6}{|l|}{ Erkek bildırcınlar } \\
\hline Sabit & 85.530 & 48.291 & 1.771 & 0.097 & \\
\hline But ağırlığı & -0.033 & 1.499 & -0.022 & 0.983 & -0.010 \\
\hline Göğüs ağırlı̆̆ 1 & 0.921 & 0.753 & 1.222 & 0.240 & 0.359 \\
\hline Kanat ağırlı̆̆g & 2.483 & 3.622 & 0.685 & 0.504 & 0.243 \\
\hline Sirt ağırlığ 1 & 0.176 & 0.632 & 0.278 & 0.785 & 0.106 \\
\hline \multicolumn{6}{|l|}{$\mathrm{R}^{2}=0.172$} \\
\hline \multicolumn{6}{|l|}{ Dişi bıldırcınlar } \\
\hline Sabit & -0.900 & 36.194 & -0.025 & 0.980 & \\
\hline But ağırlı̆̆ & 2.114 & 1.001 & 2.113 & 0.052 & 0.249 \\
\hline Göğüs ağırlığ 1 & 1.199 & 0.333 & 3.600 & 0.003 & 0.486 \\
\hline Kanat ağırlı̆̆ & 1.876 & 2.989 & 0.628 & 0.540 & 0.062 \\
\hline Sirt ağırlığ1 & 1.107 & 0.314 & 3.532 & 0.003 & 0.466 \\
\hline $\mathrm{R}^{2}=0.820$ & & & & & \\
\hline
\end{tabular}


Çizelge 3. Japon bıldırcınlarında incelenen değişkenler arasındaki korelasyon katsayıları

\begin{tabular}{|c|c|c|c|c|}
\hline \multicolumn{5}{|c|}{ Bildırcınlar (Erkek+Dişi) } \\
\hline & $\mathrm{Y}$ & $\overline{X_{1}}$ & $\overline{X_{2}}$ & $\overline{X_{3}}$ \\
\hline$\overline{X_{1}}$ & $0.542 * *$ & & & \\
\hline $\mathrm{X}_{2}$ & $0.775^{* *}$ & $0.413 * *$ & & \\
\hline $\mathrm{X}_{3}$ & $0.436 * *$ & $0.635^{* *}$ & 0.268 & \\
\hline $\mathrm{X}_{4}$ & $0.367 *$ & -0.281 & $0.408 * *$ & -0.222 \\
\hline \multicolumn{5}{|c|}{ Erkek bildırcınlar } \\
\hline & $\bar{Y}$ & $\overline{X_{1}}$ & $\overline{X_{2}}$ & $\overline{X_{3}}$ \\
\hline $\mathrm{X}_{1}$ & 0.129 & & & \\
\hline $\mathrm{X}_{2}$ & 0.370 & 0.092 & & \\
\hline $\mathrm{X}_{3}$ & 0.125 & $0.703 * *$ & -0.125 & \\
\hline $\mathrm{X}_{4}$ & 0.103 & $-0.618 * *$ & 0.404 & -0.631 \\
\hline \multicolumn{5}{|c|}{ Dişi bıldırcınlar } \\
\hline & $\mathrm{Y}$ & $\mathrm{X}_{1}$ & $\mathrm{X}_{2}$ & $\mathrm{X}_{3}$ \\
\hline $\mathrm{X}_{1}$ & 0.337 & & & \\
\hline $\mathrm{X}_{2}$ & $0.797 * *$ & 0.247 & & \\
\hline $\mathrm{X}_{3}$ & 0.328 & 0.133 & 0.245 & \\
\hline $\mathrm{X}_{4}$ & $0.702 * *$ & -0.087 & $0.499 *$ & 0.224 \\
\hline
\end{tabular}

$* \mathrm{P}<0.05, * * \mathrm{P}<0.01$

Çizelge 4. Japon bıldırcınları karkas parçaları ölçüleri için doğrudan ve dolaylı etkiler

\begin{tabular}{|c|c|c|c|c|c|c|c|c|c|c|}
\hline & & \multicolumn{3}{|c|}{ Bıldırcınlar (Erkek+Dişi) } & \multicolumn{3}{|c|}{ Erkek bildırcin } & \multicolumn{3}{|c|}{ Dişi bıldırcın } \\
\hline $\begin{array}{l}\text { Doğ. } \\
\text { E. }\end{array}$ & $\begin{array}{l}\text { Dol. } \\
\text { E. }\end{array}$ & $\mathrm{r}$ & $\mathrm{Pa}$ & E. P. $(\%)$ & $\mathrm{r}$ & $\mathrm{Pa}$ & $\begin{array}{l}\text { E. P. } \\
(\%)\end{array}$ & $\mathrm{r}$ & $\mathrm{Pa}$ & $\begin{array}{l}\text { E. P. } \\
(\%)\end{array}$ \\
\hline $\mathrm{X}_{1}$ & & $0.542 * *$ & 0.323 & 45.423 & 0.129 & -0.010 & 3.510 & 0.337 & 0.249 & 59.519 \\
\hline & $\mathrm{X}_{2}$ & & 0.195 & 27.320 & & 0.033 & 11.821 & & 0.120 & 28.794 \\
\hline & $\mathrm{X}_{3}$ & & 0.109 & 15.282 & & 0.171 & 61.292 & & 0.008 & 1.985 \\
\hline & $\mathrm{X}_{4}$ & & -0.085 & 11.975 & & -0.065 & 23.377 & & 0.041 & 9.703 \\
\hline $\mathrm{X}_{2}$ & & $0.775^{* *}$ & 0.472 & 60.829 & 0.370 & 0.359 & 82.900 & 0.797 & 0.488 & 61.167 \\
\hline & $\mathrm{X}_{1}$ & & 0.133 & 17.251 & & -0.001 & 0.208 & & 0.061 & 7.714 \\
\hline & $\mathrm{X}_{3}$ & & 0.046 & 5.931 & & -0.030 & 7.032 & & 0.015 & 1.918 \\
\hline & $\mathrm{X}_{4}$ & & 0.124 & 15.989 & & 0.043 & 9.860 & & 0.233 & 29.201 \\
\hline $\mathrm{X}_{3}$ & & $0.436^{* *}$ & 0.172 & 30.045 & 0.125 & 0.243 & 67.282 & 0.329 & 0.062 & 18.981 \\
\hline & $\mathrm{X}_{1}$ & & 0.206 & 36.010 & & -0.007 & 1.904 & & 0.033 & 10.070 \\
\hline & $\mathrm{X}_{2}$ & & 0.126 & 22.133 & & -0.045 & 12.394 & & 0.119 & 36.332 \\
\hline & $\mathrm{X}_{4}$ & & -0.067 & 11.812 & & -0.067 & 18.419 & & 0.114 & 34.617 \\
\hline $\mathrm{X}_{4}$ & & $0.367 *$ & 0.304 & 48.587 & 0.103 & 0.106 & 25.746 & 0.702 & 0.466 & 62.579 \\
\hline & $\mathrm{X}_{1}$ & & -0.091 & 14.552 & & 0.006 & 1.477 & & 0.022 & 2.905 \\
\hline & $\mathrm{X}_{2}$ & & 0.192 & 30.770 & & 0.145 & 35.332 & & 0.243 & 32.640 \\
\hline & $\mathrm{X}_{3}$ & & -0.038 & 6.091 & & -0.154 & 37.446 & & 0.014 & 1.875 \\
\hline
\end{tabular}

* $\mathrm{P}<0.05$, ** $\mathrm{P}<0.01$; Doğ. E: Doğrudan etki, Dol. E.: Dolaylı etki, r: Korelasyon katsayısı, Pa: Path katsayısı,

E. P. (\%): Etki payı, $\mathrm{X}_{1}$ : But ağırlığı, $\mathrm{X}_{2}$ : Göğüs ağırlığı, $\mathrm{X}_{3}$ : Kanat ağırlığı, $\mathrm{X}_{4}$ : Sirt ağırlığ1

But ağırlı̆̆ı, Yolcu ve ark. (2006) değerlerine yakın çıkmıştır. Kosshak ve ark. (2014), but ağırlığını 24.91$26.35 \mathrm{~g}$ arasında tespit etmişlerdir. Yapılan bir araştırmada da but ağırlığı dişi bıldırcınlarda 29.5-34.4 g bulunurken; erkek bildırcınlarda 32.1-33.1 g arasında değerler almıştır (İnci ve ark. 2015).

Sırt ağırlığı, Söğüt ve ark. (2015)'nın elde ettikleri değere yakın bulunmuştur. Bu konuda yapılan bir çalışmada Tufan ve ark. (2014), Japon bıldırcınlarında oransal sırt ağırlığını 14.91-19.68 g arasında tespit ederken; Ocak ve Erener (2005), sırt ağırlığını 16.8-18.1 g arasında saptamıştır. Bu değerler, denemede saptanan sırt ağırlığı ortalamalarından düşük bulunmuştur.

Japon bıldırcını karkas parçaları ölçülerine ait karkas ağırlığ $1(Y)$, but ağırlığı $\left(X_{1}\right)$, göğüs ağırlığı $\left(X_{2}\right)$, kanat ağırlığı $\left(X_{3}\right)$ ve sirt ağırlığına $\left(X_{4}\right)$ ait standardize edilmiş çoklu regresyon modelleri tüm bildırcınlar, erkek ve dişi bıldırcınlar için sırasıyla aşağıdaki gibi bulunmuştur. 


$$
\begin{aligned}
& Y_{\text {Genel }}=0.323 \mathrm{X}_{1}+0.472 \mathrm{X}_{2}+0.172 \mathrm{X}_{3}+0.304 \mathrm{X}_{4} \\
& \mathrm{Y}_{\text {Erkek }}=-0.010 \mathrm{X}_{1}+0.359 \mathrm{X}_{2}+0.243 \mathrm{X}_{3}+0.106 \mathrm{X}_{4} \\
& \mathrm{Y}_{\text {Disi }}=0.249 \mathrm{X}_{1}+0.486 \mathrm{X}_{2}+0.062 \mathrm{X}_{3}+0.466 \mathrm{X}_{4}
\end{aligned}
$$

Burada katsayılar standardize edildiği için sabit terim sifir olmuştur. Bulunan bu denklemde kısmi regresyon katsayıları her bir değişkenin yani but, göğüs, kanat ve sırt ağırlıklarının sonuç değişkeni olan karkas ağırlıkları üzerine doğrudan etkilerini göstermektedir. Standardize edilmiş ve normal regresyon katsayıları, standart hata, $\mathrm{t}$ istatistikleri ve önem düzeyleri ile $\mathrm{R}^{2}$ değerleri tüm bıldırcınlar, erkek ve dişi bıldırcınlar için ayrı ayrı olarak Çizelge 2'de sunulmuştur. Genel (erkek+dişi), erkek ve dişi bıldırcınlarda regresyon analizi sonucunda $\mathrm{R}^{2}$ değerleri sirasıyla $0.727,0.172$ ve 0.820 olarak bulunmuştur. Erkek+dişi bildırcınlarda karkas ağırlığı $\left(\mathrm{R}^{2}=0.727\right)$, but ağırlığı, göğüs ağırlığ1, kanat ağırlığı ve sirt ağırlığı değişkenleri tarafindan açıklanabilmiştir. Benzer şekilde erkek ve dişi bıldırcınlarda karkas ağırlığı sözü edilen değişkenler tarafindan sirasiyla $\% 17.2$ ve $\% 82.0$ olarak açıklanabilmiştir. Bir başka değişle hesaplanan $\mathrm{R}^{2}$ değerleri oluşturulan regresyon modelini açıklama değerleridir.

Japon bıldırcınlarında üzerinde durulan değişkenlere ait korelasyon katsayıları ve önem düzeyleri Çizelge 3'de sunulmuştur. Tüm bıldırcınlar için karkas ağırlığ ile but ağırlığı, göğüs ağırlığı, kanat ağırlığı ve sirt ağırlığı arasındaki korelasyon katsayıları istatistiksel olarak önemli bulunmuştur $(\mathrm{P}<0.01$ ve $\mathrm{P}<0.05)$. But ağırlığı ile göğüs ağırlığı ve kanat ağırlığı, göğüs ağırlığı ve sırt ağırlığı arasındaki korelasyonlar önemli bulunmuştur $(\mathrm{P}<0.01)$.

Erkek bildırcınlarda, but ağırlığ 1 ile kanat ve sirt ağırlıkları arasındaki korelasyonlar önemli $(\mathrm{P}<0.01)$, dişi bıldırcınlarda karkas ağırlığı ile göğüs ağırlığı ve sırt ağırlığı $(\mathrm{P}<0.01)$ ve göğüs ağırlığı ile sirt ağırlığ arasındaki korelasyonlar önemli bulunmuştur $(\mathrm{P}<0.05)$. Söz konusu korelasyon katsayıları Alkan ve ark. (2010)'nın buldukları değerden daha yüksek çıkmıştır. Kosshak ve ark. (2014), Japon bıldırcınları için yetiştirme programı planlanırken, yüksek korelasyonların göz önüne alınmasının gerekliliğine dikkati çekmiştir. Bıldırcınlarda karkas ölçülerine ilişkin korelasyon katsayıları Çizelge 3'de verilmiştir.

Eşitlik (1)'de tanımlanan path katsayıları ve Eşitlik (2)'de ifade edilen korelasyon katsayıları yardımıyla karkas ağırlığına etki eden karkas parçaları ölçülerinin doğrudan ve dolaylı etkileri tespit edilmiştir. Tespit edilen bu etkilerin değerleri tüm bildırcınlar, erkek ve dişi bıldırcınlar için Çizelge 4'de verilmiştir.

Model parametreleri incelendiğinde, tüm bıldırcınlarda but ağırlığı bir birim değiştiğinde karkas ağırlığının 0.323 birim değişeceği, göğüs ağırlığı bir birim değiştiğinde karkas ağırlığının 0.472 birim değişeceği, sırt ağırlığ 1 bir birim değiştiğinde karkas ağırlığının 0.304 birim değişeceği görülmektedir.
Erkek bildırcınlarda göğüs ağırlığ değiştiğinde karkas ağırlığının 0.359 birim değişeceği, kanat ağırlığ 1 bir birim değiştiğinde karkas ağırlığının 0.243 birim değişeceği; dişi bıldırcınlarda but ağırlı̆̆ bir birim değiștiğinde karkas ağırlığının 0.488 birim değișeceği ve sırt ağırlığı bir birim değiştiğinde karkas ağırlığının 0.466 birim değişeceği görülmektedir. Bu değişmeler doğrudan etkilerdir.

Korelasyonu açıklama payları etki payı (\%) olarak verilmiştir. Karkas ağırlığı ile but ağırlığı arasında korelasyon katsayısı 0.542 olarak bulunmuştur. 0.542 'nin 0.195 'ini \% 27.320 ile but ağırlığının göğ̈̈s ağırlığı üzerinden dolaylı etkisini açıklarken; 0.109'unu \% 15.282 ile but ağırlığının kanat ağırlığı üzerinden; 0.085 'ini \%11.975 ile but ağırlığının sırt ağırlığı üzerinden yaptığı dolaylı etkiler açıklanmıştır. Karkas ağırlığı ile göğüs ağırlığı arasındaki korelasyon katsayıs1 0.775 olarak hesaplanmıştır. Bu korelasyon unsurlara ayrıldığında 0.133 'ün \%17.251 ile göğüs ağırlığının but ağırlığı üzerinden yaptığı dolaylı etkiyi açıklarken; 0.046'sının \%5.931 ile gögüs ağırlığının kanat ağırlığ1 üzerinden; 0.124'ünün \%15.989 ile göğüs ağırlığının sırt ağırlığı üzerinden yaptığı dolaylı etkiler açıklanmıştır.

Karkas ağırlığı ile kanat ağırlığı arasında korelasyon katsayısı 0.436 olarak bulunmuştur. Söz konusu korelasyon unsurlarına ayrıldığında, 0.206'sının \% 36.010 ile kanat ağırlığının but ağırlığı üzerinden yaptığı dolaylı etkiyi açıklarken; 0.126'sının \%22.133 ile kanat ağırlığının göğüs ağırlığı üzerinden; 0.067 'sinin \% 11.812 ile kanat ağırlığının sırt ağırlığı üzerinden yaptığı dolaylı etkiler açıklanmıştır.

Karkas ağırlığı ile sirt ağırlığ katsayısı 0.367 'dir. Korelasyon unsurlarına ayrıldığında, -0.091'inin \% 14.552 ile sirt ağırlığının but ağırlığı üzerinden yaptığı dolaylı etki olup; 0.192'sinin \% 30.770 ile sırt ağırlığının göğüs ağırlığı üzerinden; 0.038'inin \%6.091 ile sirt ağırlı̆̆ının kanat ağırlığ1 üzerinden yaptığı dolaylı etkilerdir.

Erkek bıldırcınlarda; karkas ağırlığı ile but ağırlığı arasındaki korelasyon katsayısı 0.129 olarak hesaplanmıştır. Hesaplanan 0.129'unun 0.033'ünü \% 11.821 ile but ağırlığının göğüs ağırlığı üzerinden dolaylı etkisini; 0.171 'ini \%61.292 ile but ağırlı̆̆ının kanat ağırlığı üzerinden; -0.065'ini \%23.377 ile but ağırlığının sırt ağırlığı üzerinden yaptığı dolaylı etkileri belirlemiştir.

Karkas ağırlığı ile göğüs ağırlığı arasındaki hesaplanan korelasyon katsayıs1 0.370'dir. Bu korelasyonun -0.001 'inin \% 0.208 ile göğ̈̈s ağırlığının but ağırlığı üzerinden yaptığı dolaylı etkiyi ifade ederken; -0.030'unu \% 7.032 ile göğüs ağırlığının kanat ağırlığ1 üzerinden; 0.043 'ünün $\% 9.860$ ile göğüs ağırlığının sırt ağırlığı üzerinden yaptığı dolaylı etkiler ifade edilmiştir.

Karkas ağırlı̆̆ 1 ile kanat ağırlığı arasında korelasyon katsayısı 0.125 olarak bulunmuştur. Korelasyon unsurlarına ayrıldığında, -0.007'sinin \%1.904 ile kanat 
ağırlığının but ağırlığı üzerinden yaptığı dolaylı etki; 0.045 'inin \%12.394 ile kanat ağırlığının göğüs ağırlığ üzerinden; -0.067'sinin \%18.419 ile kanat ağırlığının sırt ağırlığ üzerinden yaptığ 1 dolaylı etkilerdir.

Karkas ağırlığı ile sirt ağırlığı arasında korelasyon katsayıs1 0.103 olarak bulunmuştur. Bu korelasyonun, 0.006'sının \%1.477 ile sirt ağırlığının but ağırlığ üzerinden yaptığı dolaylı etki; 0.145 'inin \%35.332 ile sırt ağırlığının göğüs ağırlığı üzerinden; -0.154'ünün \% 37.446 ile sırt ağırlığının kanat ağırlığı üzerinden yaptığı dolaylı etkiler açıklanmıştır.

Dişi bıldırcınlarda; karkas ağırlığı ile but ağırlığı arasındaki korelasyon katsayısı 0.337 olarak hesaplanmıştır. Korelasyon unsurları incelendiğinde; 0.120 'sinin \%28.794 ile but ağırlığının göğüs ağırlığ üzerinden dolaylı etkisi; 0.008'ini \%1.985 ile but ağırlığının kanat ağırlığ üzerinden; -0.041'ini \% 9.703 ile but ağırlığının sırt ağırlığı üzerinden yaptığı dolaylı etkiler açıklanmıştır.

Karkas ağırlığı ile göğüs ağırlığ korelasyon katsay1s1 0.797 'dir. Korelasyon unsurlara ayrıldığında 0.061 'inin \%7.714 ile göğüs ağırlığının but ağırlığı üzerinden yaptığı dolaylı etkiyi açıklarken; 0.015'ini \%1.918 ile göğ̈ ağırlığının kanat ağırlığ üzerinden; 0.233'ünün \%29.201 ile göğüs ağırlığının sırt ağırlığı üzerinden yaptığı dolaylı etkiler açıklanmıştır.

Karkas ağırlığı ile kanat ağırlığı arasında korelasyon katsayısı 0.329 'dur. Korelasyonun 0.033 'ünün \% 10.070 ile kanat ağırlığının but ağırlığı üzerinden yaptığı dolaylı etki; 0.119'unun \%36.332 ile kanat ağırlığının göğüs ağırlığı üzerinden; 0.114'ünün \% 34.617 ile kanat ağırlığının sırt ağırlığı üzerinden yaptığı dolaylı etkilerdir.

Karkas ağırlığı ile sırt ağırlığı arasında korelasyon katsayısı 0.702 'dir. Korelasyon unsurlarına ayrıldı̆̆ında, -0.022 'sinin \%2.905 ile sirt ağırlığının but ağırlığı üzerinden yaptığı dolaylı etki iken; 0.243'ünün \% 32.640 ile sırt ağırlığının göğüs ağırlığı üzerinden; 0.014 'ünün \%1.875 ile sırt ağırlığının kanat ağırlığı üzerinden yaptığı dolaylı etkilerdir.

$\mathrm{Bu}$ çalışmada, Japon bıldırcınlarında karkas ağırlığı üzerinde etkisi olduğu düşünülen but ağırlığı, göğüs ağırlığ 1 , kanat ağırlığ1 ve sirt ağırlığının dolaylı ve dolaysız etkileri path analizi ile tahmin edilmiştir. Analiz sonuçları bıldırcınların karkas ağırlığı üzerinde but ağırlığı, göğüs ağırlığı ve sırt ağırlığının istatistiksel olarak önemli etkiler olduğunu ortaya koymaktadır. Cinsiyete göre incelendiğinde erkek bildırcınlarda karkas ağırlı̆̆ değişkenlerin istatistiksel olarak önemli etkili olmadıkları ancak dişi bıldırcınlarda karkas ağırlığı üzerinde göğüs ağırlığı ve sırt ağırlığının istatistiksel olarak önemli etkileri oldukları görülmüştür.

Araştırma sonuçlarına göre, bıldırcınlar cinsiyet ayrımı yapılmaksızın ele alındığında karkas ağırlığı ile but ağırlığı arasında pozitif yönlü bir ilişki vardır. But ağırlığındaki artış karkas ağırlığında artışa neden olmaktadır. Erkek bıldırcınlarda karkas ağırlığı ile but ağırlığı arasında negatif yönlü çok zayıf bir ilişki görünmektedir. Erkek bıldırcınlarda but ağırlığındaki artış karkas ağırlığını önemli düzeyde etkilememektedir. Dişi bıldırcınlarda karkas ağırlığ arasında pozitif yönlü bir ilișki görünmektedir. Karkas ağırlığına etki eden faktörlerden bir diğeri olan göğüs ağırlığının artması karkas ağırlığında artışa neden olmaktadır. Erkek ve dişi bıldırcınlarda karkas ağırlığ ile göğüs ağırlığı arasında pozitif yönlü bir ilişki vardır. Karkas ağırlığına en fazla etki eden değişkenin göğüs ağırlığı olduğu görülmektedir. Karkas ağırlığı ile kanat ağırlığı arasında pozitif yönlü bir ilişki olduğundan kanat ağırlığındaki artış karkas ağırlığında artışa neden olmaktadır. Ancak kanat ağırlığın karkas ağırlığına etkisi diğer etkenlere göre daha düşük düzeydedir. Karkas ağırlığ 1 üzerinde en fazla doğrudan etkiye sahip olan değișken göğüs ağırlığı olmuştur. Karkas ağırlığına doğrudan etkiyi yapan ikinci en büyük değişken ise erkek bıldırcınlarda kanat ağırlığı, dişi bıldırcınlarda sırt ağırlığ ağırlığının kanat ağırlığı üzerinden, dişi bıldırcınlarda ise göğüs ağırlığının sırt ağırlığı üzerinden karkas ağırlığı üzerinde yapmış olduğu dolaylı etki en yüksek bulunmuştur.

Üçkardeş ve ark. (2014), karkas ağırlığ üzerinde en fazla vücut ağırlığı doğrudan etki (0.8506) etmiştir. Vücut ağırlığının dolaylı etkileri sırasıyla incik çap1 üzerinden (0.6337), incik uzunluğu üzerinden (0.5265), göğüs çevresi üzerinden (0.5138) ve vücut uzunluğu (0.3981) üzerinden olmuştur. Vücut uzunluğu ise en düşük dolaylı etkiye sahip olmuştur. Vücut uzunluğunun karkas ağırlığı üzerine dolaylı etkileri vücut ağırlığı üzerinden 0.0012 , incik çapı ve göğüs çevresi üzerinden 0.0008 ve incik uzunluğu üzerinden 0.0007 olmuştur. Söz konusu çalışmadaki karkas ağırlığını etkileyen değişkenler bu çalışmadaki değişkenlerden farklı olduğundan elde edilen sonuçlar da farklı olmaktadır.

Sonuç olarak, Japon bıldırcınlarında genel olarak karkas ağırlığı üzerine göğüs ağırlığının, erkek bıldırcinlarda göğüs ağırlığı ve kanat ağırlığı, dişi bildırcınlarda göğüs ağırlığı ve sirt ağırlığının doğrudan etkisinin diğer karkas parçalarının doğrudan etkisinden daha fazla olduğu görülmüştür.

\section{KAYNAKLAR}

Akıncı, Z., Koçak, S., Tekerli, M., Akçan, A. 2005. Bıldırcın yumurtalarında kuluçka sırasında ağırlık kaybı hızının embriyonik gelişimle ilişkisi. Tavukçuluk Araşt Derg., 3(1): 31-35.

Alkan, S., Galiç, A., Karabağ, K., Balcıoğlu, M.S. 2008. Japon bildırcinlarında (Coturnix coturnix Japonica) canlı ağırlık ve yumurta verimi bakımından seleksiyonun çıkış ve 6 . hafta canlı ağırlıklarına etkisi. Hayvansal Üretim Derg., 49(1): 16-19. 
Alkan, S., Karabağ, K., Galiç, A., Karslı, T., Balcıŏ̆lu, M.S. 2010. Determination of body weight and some carcass traits in Japanese Quails (Coturnix coturnix Japonica) of different lines. Kafkas Üniv. Vet. Fak. Derg., 16(2): 277-280. DOI:10.9775/kvfd.2009.687.

Alkan, S., Karslı, T., Karabağ, K., Galiç, A. 2013. Farklı hatlardaki Japon bildırcınlarında (Coturnix coturnix Japonica) farklı kesim yaşı ve cinsiyetin karkas özelliklerine etkisi. Süleyman Demirel Üniv. Zir. Fak. Derg., 8(1): 12-18.

Alpar, R. 2011. Uygulamalı Çok Değişkenli İstatistiksel Yöntemler. Detay Yayınları No: 429, Ankara, 853.

Ayaşan, T., Baylan, M., Uluocak, A.N., Karasu, Ö. 2000. Japon bıldırcınlarında eşey ve değişik sıklıklarda barındırmanın besi özelliklerine etkisi. Tavukçuluk Araşt. Derg, 2(1): 47-50.

Ayaşan, T. 2013. Effects of dietary inclusion of protexin (probiotic) on hatchability of Japanese quails. Indian J. Anim. Sci, 83(1): 78-81.

Bahie, El-Deen, M. 2001. Genetic parameters of carcass traits in Japanese quail. Proceedings of XV European Symposium on the Quality of Poultry Meat. 9-12 September. Kuşadas1-Turkey. p. 47-52.

Baylan, M., Ayaşan, T., Uluocak, A.N., Okan, F. 1997. Bıldırcınlarda besi özelliklerinin eşeye ve haftalara göre değişimi. Trakya Bölgesi II. Hayvancılık Sempozyumu, 9-10 Ocak 1997, Trakya Üniversitesi Tekirdağ Ziraat Fakültesi Zootekni Bölümü, Bildiriler Kitab1, 331-334, Tekirdağ.

Bonos, E.M., Christaki, E.V., Florou-Paneri, P.C. 2010 Performance and carcass characteristics of Japanese quail as affected by sex or mannan oligosaccharides and calcium propionate. South African J. Anim. Sci, 40(3): 173-184. DOI: 10.4314/sajas.v40i3.2.

Camc1, Ö. 1992. Entansif bıldırcın yetiştiriciliği. Teknik Tavukçuluk Derg, 75: 44-51.

Daşdă̆, M.M., Çelik, M.Y., Satıcı, Ö., Akkuş, Z., Çelik, H.Ç. 2006. Hangi tür araştırmalarda path analizi kullanılmalıdır? Dicle Üniversitesi Tıp Fakültesi Biyoistatistik Anabilim Dalı IX Ulusal Biyoistatistik Kongresi 5-9 Eylül 2006 Zonguldak.

Gevrekci Y., Oguz I., Aksit M., Onenc A., Ozdemir D., Altan O. 2009. Heritability and variance component estimates of meat quality in Japanese quail (Coturnix coturnix Japonica). Turk J. Vet. Anim. Sci. 33:8994.

İnci, H., Sogut, B., Sengul, T., Sengul, A.Y., Taysi, M.R. 2015. Comparison of fattening performance, carcass characteristics, and egg quality characteristics of Japanese quails with different feather colors. R. Bras. Zootec, 44(11): 390-396. DOI: $10.1590 / \mathrm{S} 1806-92902015001100003$.

Kawahara, T., Saito, K. 1976. Genetic parameters of organ and body weights in the Japanese quail. Poultry Sci., 55(4):1247-1252. DOI: $10.3382 / p s .0551247$.
Khaldari, M., Pakdel, A., Mehrabani Yeganeh, H., Nejati, J. A., Berg P. 2010. Response to selection and genetic parameters of body and carcass weights in Japanese quail selected for 4-week body weight. Poult. Sci. 89(9):1834-1841.

Khaldari, M., Pakdel, A., Mehrabani Yeganeh H., Nejati Javaremi, A., Berg P. 2011. Response to family selection and genetic parameters in Japanese quail selected for four week breast weight. Archiv Tierzucht 54(2): 212-223.

Khaldari, M., Ghiasi, H. 2015. Comparision of direct and indirect response to selection for breast weight in Japanese quail. Iranian Journal of Applied Animal Science, 5(4): 957-963.

Kosshak, A.S., Dim, N.I., Momoh, O.M., Gambo, D. 2014. Effect of sex on carcass characteristics and correlation of body weight and blood components in Japanese quails. IOSR J. Agric. and Vet. Sci, 7(11): 72-76.

Lotfi E., Zerehdaran S., Ahani Azari M. 2011. Genetic evaluation of carcass composition and fat deposition in Japanese quail. Poult. Sci. 90:2202-2208.

Marks, H.L. 1991. Divergent selection for growth in Japanese quail under split and complete nutritional environments. 5. feed intake and efficiency patterns following ninteen generations of selection. Poultry Sci, 70: 1047-1056. DOI: 10.3382/ps.0701047.

Mendeş, M., Karabayir, A., Pala, A., 2005. Path analysis of the relationships between various body measures and live weight of American Bronze Turkeys under the three different lighting programs. The Journal of Agric. Sci, 11(2): 184-188.

Narinç, D., Karaman, E., Aksoy, T. 2010. Estimation of genetic parameters for carcass traits in Japanese quail using Bayesian methods. S. Afr. J. Anim. Sci. 40(4): 342-347.

Narinç, D., Aksoy, T., Karaman, E., Aygün, A., Fırat, M. Z., Uslu, M. K. 2013. Japanese quail meat quality: Characteristics, heritabilities and genetic correlations with some slaughter traits. Poultry Science, 92(7): 1735-1744.

Narinç, D., Karaman, E., Aksoy. 2014. Effects of slaughter age and mass selection on slaughter and carcass characteristics in 2 lines of Japanese quail. Poultry Science, 93(3): 762-769.

Narinç, D., Aksoy, T., Kaplan, S. 2015. Effects of multi-trait selection on phenotypic and genetic changes in Japanese quail (Coturnix coturnix Japonica) The Journal of Poultry Science. doi: 10.2141/jpsa.0150068.

Ocak, N., Erener, G. 2005. The effects of restricted feeding and feed form on growth, carcass characteristics and days to first egg of Japanese Quail (Coturnix coturnix Japonica). AsianAustralian J. Anim. Sci, 18(10): 1479-1484. DOI: $10.5713 /$ ajas.2005.1479. 
Oğuz, İ., Akşit, M., Önenç, A., Gevrekçi, Y., Özdemir, D., Atlan, Ö. 2004a. Genetic variability of meat quality characteristics in Japanese quail (Coturnix coturnix Japonica). Arch für Geflüg, 68(4): 176181.

Oğuz, İ., Akşit, M., Önenç, A., Gevrekçi, Y., Özdemir, D., Çınar, M.U., Altan, Ö. 2004b. Heritability estimates of meat quality characteristics in Japanese quail (Coturnix coturnix Japonica). XXII. World's Poultry Congress. In G4; Genetic aspects of qualitysafety of meat. June 8-13, İstanbul.

Oğuz, İ., Minvielle, F. 2001. Effects of genetics and breeding on carcass and meat quality of Japanese quail: A review. Proceedings of XV European Symposium on the Quality of Poultry Meat. 9-12 September. Kuşadas1-Turkey. p. 41-46.

Pedhazur, E.J. 1997. Multiple regression in behavioral research. Harcourt Brace College Publishers, Forth Worth, $1057 \mathrm{p}$.

Pek, H. 1999. Nedensel modeller. Gazi Üniversitesi Fen Bilimleri Enstitüsü, Yüksek Lisans Tezi, Ankara.

Poyraz, Ö., Akıncı, Z., Erdoğan, M., Güler, Ş. 2002. Bildırcinlarda cinsel olgunluk mevsiminin bazı yumurta kalite özelliklerine etkisi. Lalahan Hayv. Araşt. Enst. Derg, 42(1): 45-58.

Pym, R.A.E., Popovic, B., Bodero, D.A.V. 1998. Selection for breast meat yield in Japanese quail (Coturnix coturnix Japonica) using real time ultrasound. Proceedings of the 6th World Congress on Genetics Applied to Livestock Production. 11-16 January, Armidale, NSW, Australia, 24, 290-293.

Sar1, M., Tilki, M., Saatci, M. 2011. Genetic parameters of slaughter and carcase traits in Japanese quail (Coturnix coturnix Japonica). Br. Poult. Sci. 52(2):169-172.

Singh, R.V., Tewari, N., Singh, C.V., Singh, Y.P. 1988. Path coefficient analysis of mineral in blood serum affecting first lactation milk yield in crossbred cows. Indian J. Anim. Sci, 58(8): 994-996.

Sokal, R.R., Rohlf F.J. 1995. 3rd edition. Biometry. W.H. Freeman and Company. 885 p. Newyork.

Söğüt, B., Çelik, Ş., İnci, H., Şengül, T., Daş, A. 2015. Farklı tüy rengine sahip Japon bildırcınlarda bazı vücut ağırlığ verilerinin Friedman ve Quade testleriyle belirlenmesi. Türk Tarım ve Doğa Bilim Derg, 2(2): 171-177.
Tarhyel, R, Tanimomo, B. K, Hena, S. A. 2012. Organ weight: As Influenced by color, sex and weight group in Japanese quail. Scientific Journal of Animal Science, 1(2): 46-49.

Toelle, V.D., Havenstein, G.B., Nestor, K.E., Harvey, W.R. 1991. Genetic and phenotypic relationships in Japanese quail. 1. Body weight, carcass, and organ measurements. Poultry Sci, 70(8): 1679-1688. DOI: $10.3382 /$ ps.0701679.

Tufan, C., Arslan, C., Sarı, M. 2014. Japon bildırcını rasyonlarına farklı oranlarda klinoptilolit ilavesinin besi performansı, karkas verim özellikleri ve bazı kan parametrelerine etkisi. Lalahan Hay. Araș. Enst. Derg, 54(1): 21-27.

Üçkardeş, F., Narinç, D., Küçükönder, H. 2014. Establishment of optimum regression model and determination of relationships between body measurements and slaughter traits in Japanese quails by path analysis. Animal Production Science, 55(6): 799-803. http://dx.doi.org/10.1071/AN13357.

Vatansever, H. 1998. B1ldırcın Üretim Sistemleri. Tarım Bakanlığ 1 , Ankara, $100 \mathrm{~s}$.

Wyatt, J.M.F., Siege, P.B., Cherry, J.A. 1982. Phenotypic relationships between adipostiy, breast weight and body weight in female Japanese quail. Poultry Sci, 61(4): 643-646. doi: 10.3382/ps.0610643.

Yakubu, A., Salako, A.E. 2009. Path coefficient analysis of body weight and morphological traits of Nigerian indigenous chickens. Egyptian Poultry Sci, 29(III): 837-850.

Yolcu, H.İ., Balcioğlu, M.S., Karabağ, K., Şahin, E. 2006. Japon bıldırcınlarında canlı ağırlık için yapılan iki yönlü seleksiyonun ve cinsiyetin karkas ve bazı organ ağırlıklarına etkileri. Akdeniz Üniv. Zir. Fak. Derg, 19(2): 185-189.

Zerehdaran S, Lotfi E, Rasouli Z. 2012. Genetic evaluation of meat quality traits and their correlation with growth and carcase composition in Japanese quail. Br. Poult. Sci. 53(6): 756-762. doi: 10.1080/00071668.2012.746445. 